\title{
CYTOLOGICAL DIAGNOSIS OF GELATINOUS ASCITES
}

Samith Ahmed, Farhana Zakaria, Aravind P.

1. Post Graduate. Department of Pathology, A. J. Institute of Medical Sciences (AJIMS), Mangalore.

2. Assistant Professor. Department of Pathology, A. J. Institute of Medical Sciences (AJIMS), Mangalore.

3. Associate Professor. Department of Pathology, A. J. Institute of Medical Sciences (AJIMS), Mangalore.

\section{CORRESPONDING AUTHOR:}

Samith Ahmed,

Gulisten, K. E. Compound,

Mulihitlu Road, Bolar,

Mangalore- 575001.

E-mail: samith_17@yahoo.com

ABSTRACT: Pseudomyxoma peritonei (PMP) is a condition characterized by the accumulation of mucinous material in the peritoneal cavity (gelatinous ascites).

Pseudomyxoma peritonei is an uncommon condition in which mucinous ascites causes progressive abdominal distension and gastrointestinal dysfunction. We present a case of 44 year old female who presented with gradually progressive abdominal distension since 6 months. An ascitic tap was performed and the fluid was sent for cytological study. Cytology showed pools of acellular mucin. On laparotomy there was mucinous material in the abdomen that was evacuated. Appendix and omentum were found to be thickened, hence appendicectomy was done and omental biopsy taken. Histopathological diagnosis of well differentiated mucinous adenocarcinoma of appendix with rupture and mucinous ascitis was made.

KEYWORDS: Pseudomyxoma peritonei, mucinous adenocarcinoma, appendix

INTRODUCTION: Peritoneal involvement by a mucinous neoplasm may be accompanied by extensive collections of intra-abdominal mucus, so-called "pseudomyxoma peritonei"1,2. The massive accumulation of tumor cells within the greater omentum contributes to the increase of the abdominal girth which is one of the common presentations. Pertinent cytologic features include a mucinous background with mesothelial cells and histiocytes.

CASE REPORT: This is a case of 44 years old female who presented with abdominal distension since 6 months. Ascitic fluid cytology (Figure 1and Figure 2) showed pools of mucinous material, few inflammatory cells and occasional mesothelial cells. At laparotomy mucinous material in the abdomen was evacuated. Inspection of the abdomen showed thickened appendix and omentum . Appendicectomy was performed and omental biopsy was taken.

Grossly appendix was swollen and measured $4.5 \times 3 \times 1.5 \mathrm{~cm}$ with presence of mucoid material at the tip (Figure 3). Cut-Surface showed rupture of the tip, dilated lumen with areas of haemorrhage and mucoid material. Two Omental bits were sent. Larger bit (Figure4) measured $20 \times 10 \times 2 \mathrm{~cm}$. Smaller bit measured $17 \times 7.5 \times 1 \mathrm{~cm}$.

They were covered with mucoid material and showed foci of haemorrhage. Cut-surface (Figure5) showed mucin filled small multiple cysts.

Microscopy of appendix (Figure6) showed a tumor arranged in papillae and glandular pattern. Papillae were lined by single layer of columnar cells having increased $\mathrm{N}: \mathrm{C}$ ratio, loss of stratification, round to oval vesicular nuclei with prominent nucleoli. Background showed pools 
of mucin with areas of hyalinisation. Adjacent stroma (Figure7) showed inflammatory infiltrate composed of plasma cells and eosinophils.

Sections from omentum (Figure8) showed numerous mucin filled cysts lined by a single layer of bland, mucin secreting pseudo stratified columnar epithelium with intra and extracytoplasmic mucin secretion. Stroma (Figure9) showed moderate lymphoplasmacytic inflammatory infiltrate surrounded by mature adipose tissue. A diagnosis of well differentiated mucinous adenocarcinoma of appendix with rupture and mucinous ascites was made.

DISCUSSION: Pseudomyxoma peritonei (PMP) is a rare progressive disease, characterized by the production of copious amounts of mucinous fluid that gradually fills the peritoneal cavity, resulting in the so called 'jelly belly' abdomen ${ }^{3}$. The first case was described by Rokitansky in $1842^{4}$, but the term PMP was described in 1884 in association with a mucinous carcinoma of the ovary ${ }^{5}$. Later on, in 1901 Frankel $^{6}$ described PMP in association with a cyst of the appendix.

Pseudomyxoma peritonei is thought to originate from appendiceal adenoma which occludes the lumen of the appendix followed by gradual distention of the distal part with mucus and epithelial cells till it ruptures. The location and quantity of mucinous tumor within the abdomen and pelvis is characterized by a redistribution phenomenon that accumulates along the absorptive area of peritoneal fluid e.g. greater omentum and diaphragm. In contrast the visceral peritoneum of the small bowel is seeded sparsely3.

The microscopic appearance of lesions designated pseudomyxoma peritonei in the literature has included: free mucin in the abdominal cavity (mucinous ascites); small or large deposits of mucin adherent to peritoneal surfaces, containing inflammatory and mesothelial cells and sometimes organizing capillaries and fibroblasts, but usually lacking neoplastic epithelial cells; pools of mucin, which may or may not contain neoplastic cells surrounded by dense collagenous tissue (dissecting mucin) . If neoplastic cells are present in pseudomyxoma peritonei , they are usually well-differentiated mucinous columnar cells of intestinal type.

Recent cytologic studies, of small series, have emphasized the usefulness of neoplastic epithelial cells, reactive mesothelial cells, acellular mucin, histiocytes and spindle cells in making the diagnosis of $\mathrm{PMP}^{7,8,9}$.

An interesting aspect of this disease is the mechanism behind the accumulation of extracellular mucin. It has been reported that pseudomyxoma is characterised by the production of MUC2, a gel-forming mucin that is known to form strong bonds with the stroma and is thought to have tumor suppressor activities ${ }^{10}$. The other factor that is pathogenetically responsible for the extracellular accumulation of mucin is an alteration in cell polarity, so that the secreted glycoproteins are expressed predominantly in the stroma-facing surfaces of the tumor cells.

It's worth mentioning that the literature contains sporadic cases of PMP in association with tumors of GI, lung, breast, pancreas, gallbladder, bile duct, fallopian tubes, ovaries, and urinary bladder 5 .

\section{REFERENCES:}

1. Ronnett BM, Zahn CM, Kurman RJ, Kass ME, Sugarbaker PH, Shmookler BM. Disseminated peritoneal adenomucinosis and peritoneal mucinous carcinomatosis. A clinicopathologic analysis of 109 cases with emphasis on distinguishing pathologic features, site of origin, prognosis, and relationship to pseudomyxoma peritonei. Am J Surg Pathol. 1995;19:1390-408. [ubMed] 
2. Bradley R F, Stewart J H 4th, Russell G B et al. 2006 Pseudomyxoma peritonei of appendiceal origin: a clinicopathologic analysis of 101 patients uniformly treated at a single institution, with literature review. Am J Surg Pathol 30: 551-559

3. Sugarbaker PH, Ronnett BM, Archer A, Averbach AM, Bland R, Chang D, et al. Pseudomyxoma peritonei syndrome. Adv Surg. 1996;30:233-80. [PubMed]

4. Weaver $\mathrm{CH}$. Mucocele of appendix with pseudomucinous degeneration. Am J Surg. 1937;36:523-6.

5. Hinson FL, Amrose NS. Pseudomyxoma Peritonei: a Review. British J Surg. 1998;85:1332-9.

6. Frankel E. Uber das sogenannte pseudomyxoma peritonei. Med Wochenschr. 1901;48:965-70.

7. Pfitzer P, Richartz G. Cytology of pseudomyxoma peritonei. Cytopathology 1995;6:304 -15.

8. 23. Mulvany N, Ooi K. Pseudomyxoma peritonei: a cytohistopathologic study of 9 cases. Diagn Cytopathol 1996;15: 144-50.

9. Pisharodi L, Bedrossian C, Gudlaugsson E. Cytologic diagnosis of pseudomyxoma peritonei: common and uncommon causes. Int J Surg Pathol 1995;2(Suppl.):10 13.

10. O'Connell JT, Tomlinson JS, Roberts AA, McGonigle KF, Barsky SH. Pseudomyxoma peritonei is a disease of MUC2-expressing goblet cells. Am J Pathol 2002, 161: 551-564.
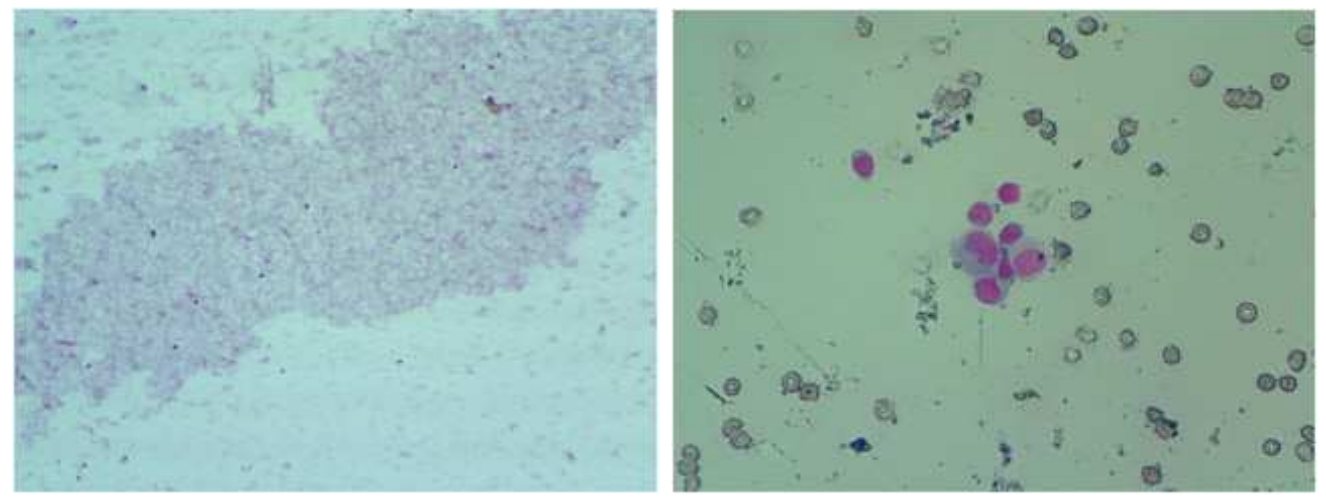

Figure1. Scanner view (40X) of Ascitic fluid Figure2. High Power view (400X) of Ascitic fluid showing pools of mucinous material. showing few inflammatory cells and Papanicolaou stain occasional mesothelial cells. Papanicolaou stain. 


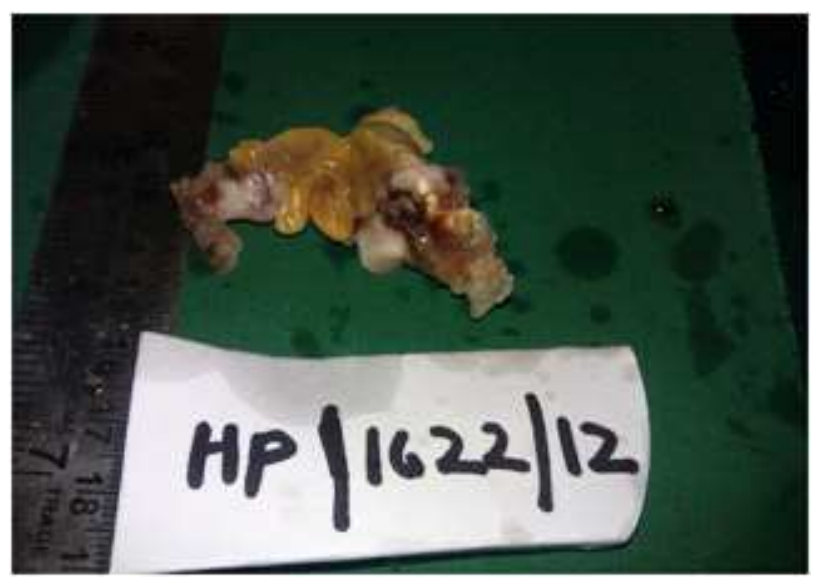

Figure3.Tip of Appendix covered with mucin. Cut surface reveals tip is ruptured, lumen is dilated showing areas of haemorrhage and mucoid material.

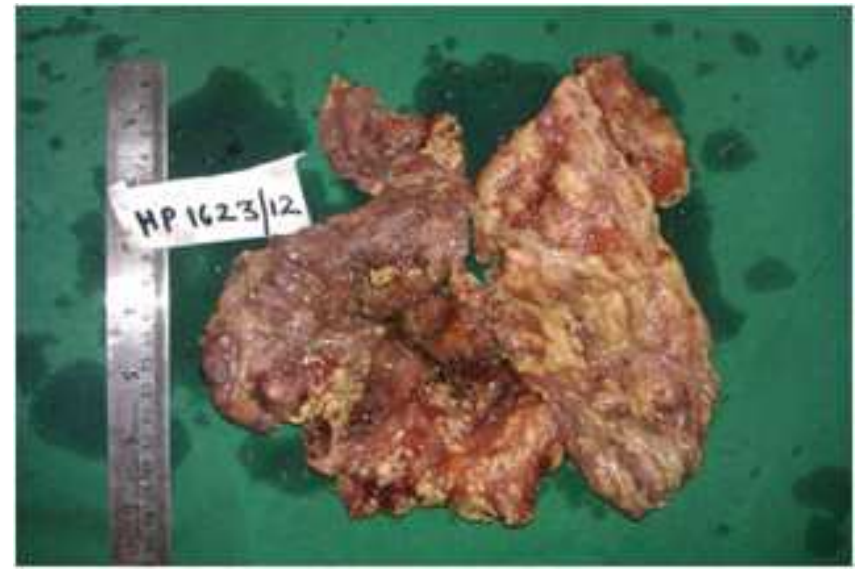

Figure4. Omentum covered with mucoid material showing foci of haemorrhage and firm in consistency.

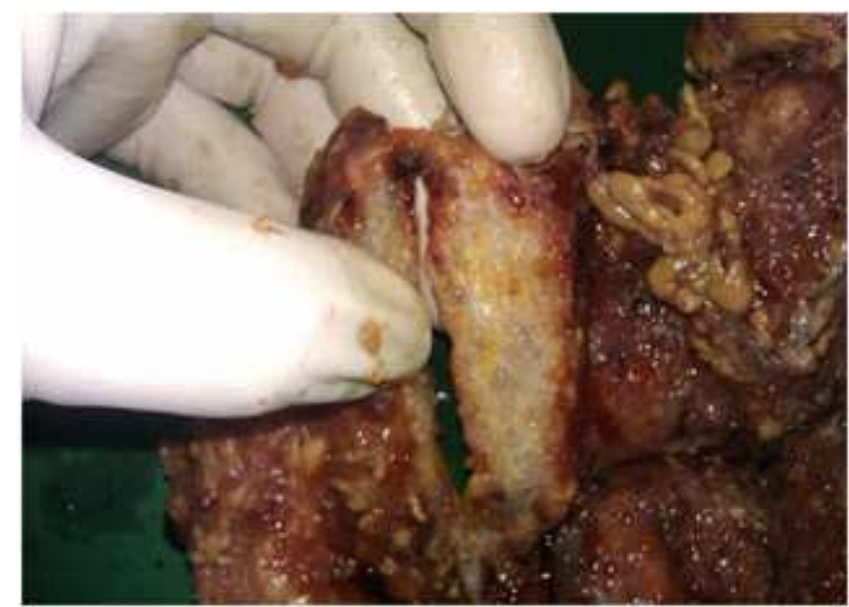

Figure5. Cut surface of Omentum reveals mucin filled small multiple cysts. 


\section{CASE REPORT}

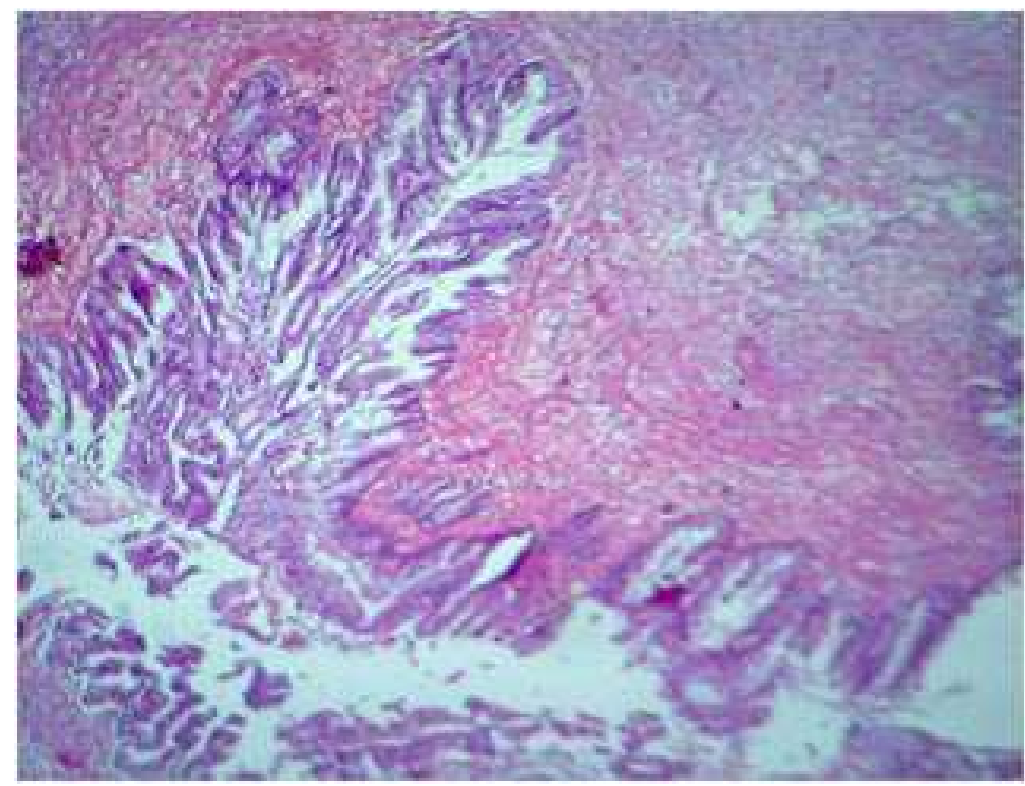

Figure6. Microscopy of appendix shows tumor arranged in papillae and glandular pattern. Papillae are lined by single layer of columnar cells having increased $\mathrm{N}: \mathrm{C}$ ratio , loss of stratification, round to oval vesicular nuclei with prominent nucleoli. Low power view (100X). H\&E stain.

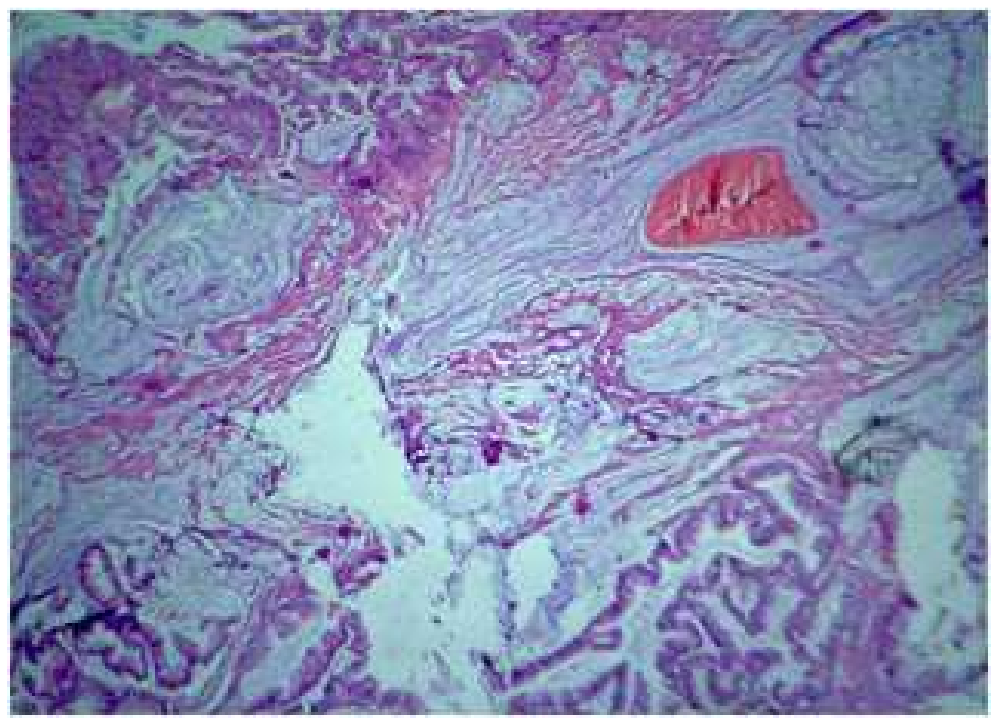

Figure7. Microscopy Scanner view (40X)The background shows pools of mucin, areas of hyalinisation .Adjacent stroma shows inflammatory infiltrate composed of plasma cells and eosinophils. H\&E stain. 


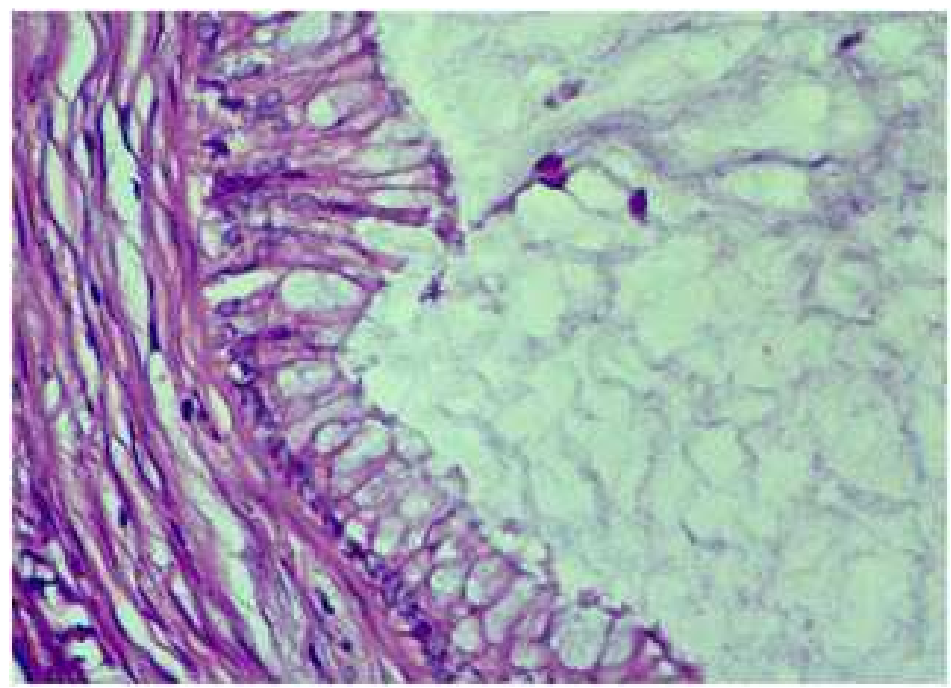

Figure8.Microscopy High power view (400X) of Omental tissue shows numerous mucin filled cysts lined by a single layer of bland, mucin secreting pseudo stratified columnar epithelium with intra and extracytoplasmic mucin secretion. H\&E stain.

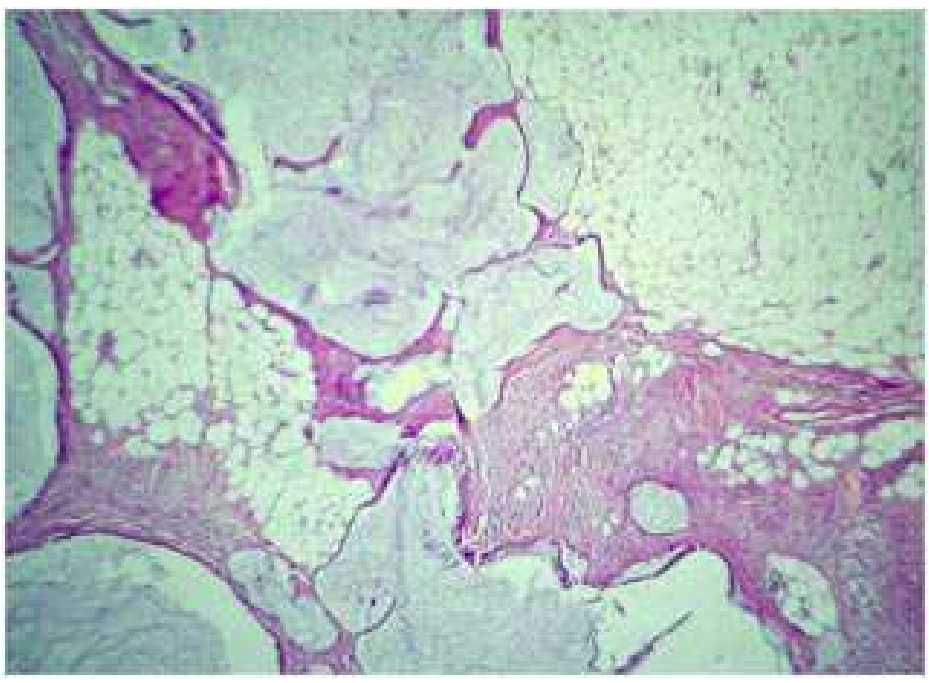

Figure9.Microscopy Scanner view (40X) Stroma shows moderate lymphoplasmacytic inflammatory infiltrate surrounded by mature adipose tissue. H\&E stain. 